\title{
Silver/Carbon Codoped Titanium Dioxide Photocatalyst for Improved Dye Degradation under Visible Light
}

\author{
P. Nyamukamba, ${ }^{1}$ L. Tichagwa, ${ }^{1}$ S. Mamphweli, ${ }^{2}$ and L. Petrik ${ }^{3}$ \\ ${ }^{1}$ Department of Pure \& Applied Chemistry, University of Fort Hare, P. Bag X1314, Alice 5700, South Africa \\ ${ }^{2}$ Fort Hare Institute of Technology, University of Fort Hare, P. Bag X1314, Alice 5700, South Africa \\ ${ }^{3}$ Chemistry Department, University of the Western Cape, P. Bag X17, Bellville 7535, South Africa \\ Correspondence should be addressed to P. Nyamukamba; pnyamukamba@ufh.ac.za
}

Received 2 October 2016; Revised 9 December 2016; Accepted 15 December 2016; Published 11 January 2017

Academic Editor: Leonardo Palmisano

Copyright (C) 2017 P. Nyamukamba et al. This is an open access article distributed under the Creative Commons Attribution License, which permits unrestricted use, distribution, and reproduction in any medium, provided the original work is properly cited.

\begin{abstract}
Herein, we report the synthesis of quartz supported $\mathrm{TiO}_{2}$ photocatalysts codoped with carbon and silver through the hydrolysis of titanium tetrachloride followed by calcination at $500^{\circ} \mathrm{C}$. The prepared samples were characterized by UV-Vis diffuse reflectance spectroscopy, high resolution scanning electron microscopy (HRSEM), Raman spectroscopy, thermogravimetric analysis (TGA), $\mathrm{X}$-ray photoelectron spectroscopy (XPS), and X-ray diffraction (XRD). Codoping of $\mathrm{TiO}_{2}$ with $\mathrm{Ag}$ and carbon resulted in an increase in the surface area of the photocatalyst and altered the ratio of the anatase to rutile phase. The absorption edge of all the doped $\mathrm{TiO}_{2}$ photocatalysts redshifted and the band gap was reduced. The lowest band gap of $1.95 \mathrm{eV}$ was achieved by doping with $0.5 \% \mathrm{Ag}$. Doping $\mathrm{TiO}_{2}$ using carbon as the only dopant resulted in a quartz supported photocatalyst that showed greater photocatalytic activity towards methyl orange than undoped $\mathrm{TiO}_{2}$ and also all codoped $\mathrm{TiO}_{2}$ photocatalysts under visible light irradiation.
\end{abstract}

\section{Introduction}

The problem related to environmental pollution has triggered much research focused on the development of efficient methods for the removal of dangerous contaminants discharged into the environment. If these contaminants are not removed, they will have an adverse impact on human health and the environment. Photocatalysis using visible light responsive $\mathrm{TiO}_{2}$ photocatalyst is an effective and economical way to reduce environmental pollution since it makes use of free sunlight and the contaminants can be mineralised completely into harmless products. The process involves the accumulation of pollutants on the photocatalyst surface which are then photodegraded by reactive species upon irradiation with light of appropriate wavelength.

Among the several semiconductors that are available such as CdS, ZnS, CdTe, ZnSe, CdSe, $\mathrm{ZnO}, \mathrm{WO}_{3}, \mathrm{CeO}_{2}$, $\mathrm{ZrO}_{2}, \mathrm{Nb}_{2} \mathrm{O}_{3}, \mathrm{Fe}_{2} \mathrm{O}_{3}$, and $\mathrm{SnO}_{2}$, titanium dioxide is the most extensively used and studied photocatalyst due to its several advantages which include chemical stability, relative nontoxicity, and low cost [1]. It has several applications which include (i) cleaning of oil spills $[2,3]$, (ii) disinfection or antibacterial activity $[4,5]$, (iii) usage as a white pigment, (iv) energy production [6], (v) water treatment $[7,8]$, and (vi) air purification [7]. The major drawback of the application of $\mathrm{TiO}_{2}$ in photocatalysis is its wide band gap of $3.2 \mathrm{eV}$ meaning that it can only absorb light of wavelength of less than $387 \mathrm{~nm}$ which is only $4 \%$ of the total incoming solar radiation. A lot of effort has been made to extend the photoresponse of the photocatalyst into the visible region which makes up 55\% of the total solar radiation.

Different approaches such as coupling with another low band gap semiconductor $[9,10]$, use of plasmon elements which can activate $\mathrm{TiO}_{2}$ under visible light through direct electron transfer [11-13], dye sensitization [6,14], and doping have been done in an effort to make $\mathrm{TiO}_{2}$ harness visible light. Among these approaches, doping with either metal, nonmetal, or both dopants has been extensively investigated, including $\mathrm{Ag}$ doping [15] or doping with $\mathrm{Nd}^{3+}, \mathrm{Pd}^{2+}, \mathrm{Pt}^{4+}$ and $\mathrm{Fe}^{3+}$ [16], $\mathrm{Au}$ [17], and $\mathrm{Co}$ [18] and nonmetal doping [19-21]. 
However, the use of metal dopants has been found to result in localised d-levels in the $\mathrm{TiO}_{2}$ band gap which can serve as recombination centres for charge carriers [22]. It is important to note that, besides making the photocatalyst visible light responsive, there are other factors that exert a considerable influence on the performance of the photocatalyst and these include size, crystalline phase, pore volume, surface area, and exposed surface facets [23], but a lot of researchers have been focusing mainly on making use of visible light by reducing the band gap. The codoping of $\mathrm{TiO}_{2}$ with a nonmetal and transition metal is therefore believed to be appropriate in narrowing the band gap with minimal recombination centres. The present paper reports the preparation of low band gap $\mathrm{TiO}_{2}$ by codoping with carbon and silver using a sol-gel method.

\section{Experimental}

2.1. Materials and Chemicals. Special grade titanium (IV) tetrachloride $99 \%$ was purchased from Merck, Germany, silver nitrate (99.8\%) was purchased from SAARCHEM, South Africa, and potassium hydroxide was purchased from Merck. All chemicals were analytical grade and used as received without further purification. Distilled water was used in all preparations of solutions.

2.2. Catalyst Preparation. A modified version of the sol-gel procedure reported in literature [20] was used to prepare the silver/carbon codoped $\mathrm{TiO}_{2}$ photocatalysts with different contents of $\mathrm{Ag}$. In a typical experiment, titanium tetrachloride $(6.0 \mathrm{~mL})$ was added dropwise to a $100 \mathrm{~mL}$ of distilled water in a flask immersed in an ice bath with vigorous stirring. An appropriate amount of glucose was added to get a final concentration of $0.01 \mathrm{M}$ of glucose in the solution. This procedure was repeated to prepare six different sets of solutions. Suitable amounts of silver solution were added to each of the six solution sets so as to get $0.2,0.5,0.7$, and $1.0 \mathrm{~mol}$ percent of $\mathrm{Ag}$, respectively, in the solutions. The solutions were then heated for 30 minutes at $95^{\circ} \mathrm{C}$ and then allowed to cool to room temperature. After cooling, the $\mathrm{pH}$ was adjusted to 8.0 using potassium hydroxide and then heated again at $95^{\circ} \mathrm{C}$ for another 30 minutes. The precipitate was separated from the solution by centrifugation, washed with deionised water to remove excess chloride ions, dried at $90^{\circ} \mathrm{C}$, and then finally calcined at $500^{\circ} \mathrm{C}$ in air for 2 hours to give $\mathrm{Ag} / \mathrm{C}$ codoped $\mathrm{TiO}_{2}$. The undoped $\mathrm{TiO}_{2}$ photocatalyst was also prepared using the same procedure but without the addition of glucose and silver. Ag doped $\mathrm{TiO}_{2}$ photocatalyst was prepared using the same procedure.

2.3. Deposition of $\mathrm{TiO}_{2}$ Photocatalysts on Quartz. The prepared $\mathrm{C}$-doped and $\mathrm{Ag} / \mathrm{C}$ codoped $\mathrm{TiO}_{2}$ photocatalysts were deposited on quartz supports using a modified version of the methodology reported by Markelonis and coworkers [24]. The method has the advantages of being fast and simple compared to other currently known nanoparticle deposition techniques. A desired amount of the prepared $\mathrm{TiO}_{2}(0.02 \mathrm{~g})$ photocatalyst was mixed with absolute ethanol
$(15 \mathrm{~mL})$ and then sonicated for five minutes to make sure that the $\mathrm{TiO}_{2}$ nanoparticles were well dispersed. The etched and 3-mercaptopropyl trimethoxysilane (MPTMS) treated quartz substrate to be coated was placed in a centrifuge vial with one side covered with sellotape so that only one side could be coated. The sonicated $\mathrm{TiO}_{2}$ nanoparticles were then poured into the centrifuge vials and centrifuged at $3500 \mathrm{rpm}$ until a significant amount was deposited. The desired amount was determined by weighing the quartz support before and after deposition. After centrifugation, the supernatant was pipetted out and the quartz substrate with the deposited $\mathrm{TiO}_{2}$ nanoparticles was then removed and allowed to dry in the air.

2.4. Characterization. The diffuse reflectance spectra (DRS) of the samples were acquired from $800 \mathrm{~nm}$ to $200 \mathrm{~nm}$ at room temperature using a diffuse reflectance attachment of a Cary 500 UV-Vis-NIR spectrophotometer. Fourier transform infrared (FTIR) spectra were obtained on a Perkin-Elmer (FTIR Spectrum 200) spectrophotometer. The powdered samples were mixed with $\mathrm{KBr}$, pressed into a pellet, and then analysed. The crystallographic characteristics of the prepared samples were analysed by a powder X-ray diffractometry (XRD) technique using a Bruker D8 Advance instrument with a $\mathrm{Cu}-\mathrm{K} \alpha 1(\lambda-1.54060) \mathrm{X}$-ray Tube and a LynxEye detector. The Raman spectra were obtained on a CzernyTurner micro-Raman spectrometer equipped with a cooled charged coupled device. The detector and beam path were set at $-50^{\circ} \mathrm{C}$ and $50 \mathrm{x}$, respectively. A red laser diode with a wavelength of $785 \mathrm{~nm}$ was used for the excitation of the samples. The specific surface areas of the powdered $\mathrm{Ag} / \mathrm{C}$ codoped $\mathrm{TiO}_{2}$ photocatalysts were obtained by $\mathrm{N}_{2}$ adsorption before deposition on quartz using a Micromeritics ASAP 2020 surface area and porosity analyser. X-ray photoelectron spectroscopy (XPS) was done using a Kratos Axis Ultra DLD, using an Al (monochromatic) anode, equipped with charge neutralizer and the operating pressure was kept below $5 \times$ $10^{-9}$ torr.

2.5. Photocatalytic Activity Evaluation. The photocatalytic activity of the synthesised $\mathrm{Ag} / \mathrm{C}$ codoped $\mathrm{TiO}_{2}$ photocatalysts was evaluated under visible light irradiation using methyl orange as a model pollutant. All photodegradation experiments were conducted at a temperature of $25^{\circ} \mathrm{C}$ and at $\mathrm{pH}$ 7. In a typical experiment, the $2.5 \mathrm{~cm} \times 3.5 \mathrm{~cm}$ photocatalyst coated quartz slide was immersed in $100 \mathrm{~mL}$ of 10 ppm methyl orange solution in a flask in such a way that there was room at the bottom of the reactor by means of a perforated plastic stand for the magnetic stirrer to rotate without scratching the photocatalyst film. The flask was wrapped with aluminium foil and then placed in the dark for an hour for adsorption and desorption equilibrium to take place. The system was then irradiated with visible light from an Oriel Newport solar simulator fitted with a $500 \mathrm{~W}$ xenon lamp. The solar simulator was Model 91150V supplied by Oriel Instruments, USA. To detect the changes in methyl orange concentration with time, aliquots of methyl orange were taken after every 30 minutes and analysed by a UV-Vis spectrometer at a wavelength of $468 \mathrm{~nm}$. 


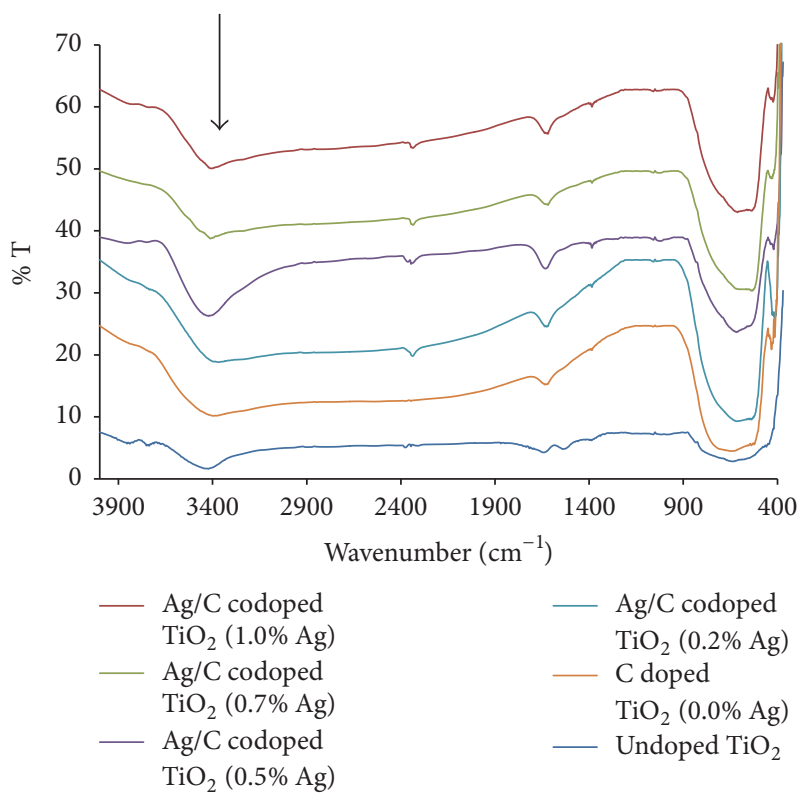

Figure 1: FTIR spectra of undoped $\mathrm{TiO}_{2}$ and Ag/C codoped $\mathrm{TiO}_{2}$ photocatalysts with different $\mathrm{Ag}$ contents.

\section{Results and Discussion}

3.1. FTIR Analysis. The FTIR analysis was done to study the changes in the surface of the codoped photocatalysts as the Ag dopant level was increased and also to determine the functional groups. The FTIR spectra in the region between $400 \mathrm{~cm}^{-1}$ and $4000 \mathrm{~cm}^{-1}$ of undoped $\mathrm{TiO}_{2}, \mathrm{C}$-doped $\mathrm{TiO}_{2}$, and $\mathrm{Ag} / \mathrm{C}$ codoped $\mathrm{TiO}_{2}$ photocatalysts are shown in Figure 1 and they all have similar peaks but with different intensities. The peaks around $3450 \mathrm{~cm}^{-1}$ and $1655 \mathrm{~cm}^{-1}$ were assigned to the stretch vibration and characteristic frequency of $\mathrm{O}-\mathrm{H}$ groups bending of adsorbed water, respectively [25]. These were more intense in the spectrum of the photocatalyst with Ag loading of $0.5 \%$. This probably implies that this particular photocatalyst adsorbed water more than the other photocatalysts which could be useful in photocatalytic reactions because the adsorbed water can be attacked by positive holes to produce hydroxyl radicals. The pronounced broad band in the range $400-900 \mathrm{~cm}^{-1}$ was assigned to the stretching vibration of the Ti-O bond and it was common in the spectra of all samples. The peak at $2358 \mathrm{~cm}^{-1}$ due to the presence of carbon species [26] is found in the spectra of all samples except $\mathrm{TiO}_{2}$ that had $\mathrm{Ag}$ content of $0.0 \%$ and also undoped $\mathrm{TiO}_{2}$. The undoped $\mathrm{TiO}_{2}$ is the only photocatalyst that had a peak at $1557 \mathrm{~cm}^{-1}$.

3.2. XRD Analysis. X-ray diffraction analysis was carried out to determine the crystalline nature of the $\mathrm{Ag} / \mathrm{C}$ codoped $\mathrm{TiO}_{2}$ nanoparticles. The XRD patterns of the prepared photocatalysts are shown in Figure 2 . The peaks at $2 \theta 25.1^{\circ}, 37.6^{\circ}, 47.8^{\circ}$, $53.9^{\circ}, 56.2^{\circ}, 62.5^{\circ}, 68.8^{\circ}, 70.4^{\circ}, 74.8^{\circ}$, and $82.4^{\circ}$ correspond to the diffraction of (101), (004), (200), (105), (211), (204), (116), (301), (215), and (224) crystal faces of the anatase phase of $\mathrm{TiO}_{2}$ [27]. The peaks at $27.6^{\circ}, 36.1^{\circ}, 41.1^{\circ}, 43.81^{\circ}, 54.6^{\circ}$, and

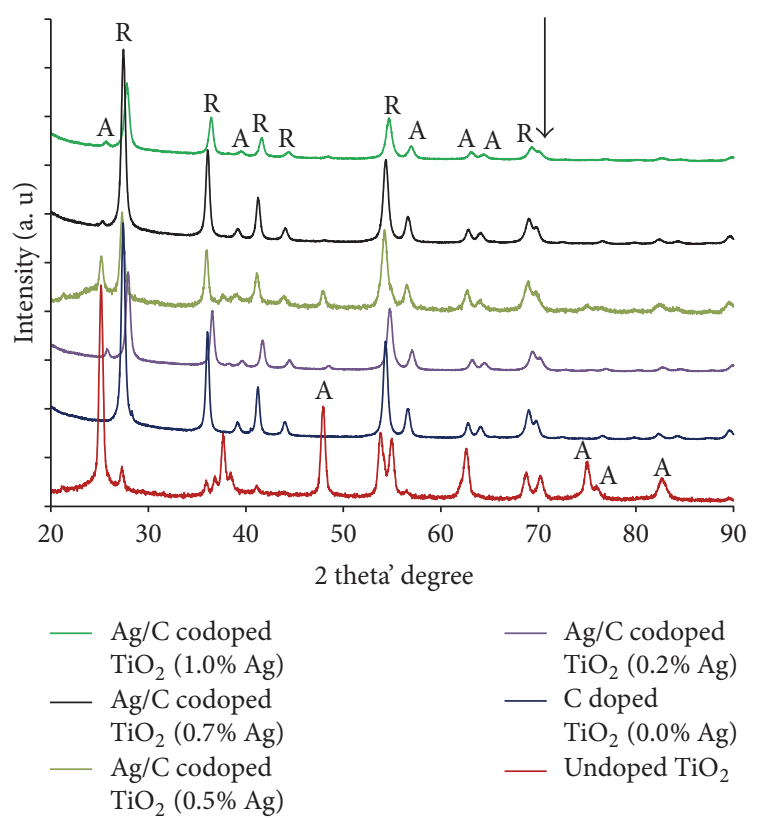

FIgURE 2: XRD patterns of undoped $\mathrm{TiO}_{2}$ and $\mathrm{Ag} / \mathrm{C}$ codoped $\mathrm{TiO}_{2}$ photocatalyst powders with different contents of Ag prepared by a solo-gel method.

$68.4^{\circ}$ were due to the (110), (101), (200), (210), (220), and (301) mirror planes of the rutile phase.

When the XRD pattern of undoped $\mathrm{TiO}_{2}$ photocatalyst is compared with the XRD pattern of doped $\mathrm{TiO}_{2}$ photocatalysts, the relative intensities of some peaks and peak areas, for instance, at $2 \theta=47.8^{\circ}$, were altered due to lattice distortions and changes in the degree of crystallinity caused by the conditions applied.

The XRD results showed that Ag and carbon codoping of $\mathrm{TiO}_{2}$ altered the ratio of anatase to rutile phase present. For instance, in the XRD pattern of undoped $\mathrm{TiO}_{2}$, the most intense peak at $2 \theta=25.1^{\circ}$ due to the anatase phase reduced significantly in the XRD pattern of $\mathrm{Ag} / \mathrm{C}$ codoped $\mathrm{TiO}_{2}$ photocatalysts and it completely disappeared in the XRD pattern of C-doped $\mathrm{TiO}_{2}$ photocatalyst. The peaks at $2 \theta=$ $27.3^{\circ}, 36.2^{\circ}$, and $41.1^{\circ}$ that are assigned to the rutile phase were of low intensities in the XRD pattern of undoped $\mathrm{TiO}_{2}$ but increased in intensity in the XRD patterns of all doped $\mathrm{TiO}_{2}$ photocatalysts indicating partial phase transformation had occurred by doping with Ag or carbon. There was a new peak at $2 \theta$ value of $43.8^{\circ}$ due to rutile which was nonexistent in the XRD pattern of undoped $\mathrm{TiO}_{2}$ but present in the XRD pattern of all doped $\mathrm{TiO}_{2}$ samples. The major phase in the C-doped $\mathrm{TiO}_{2}(0.0 \% \mathrm{Ag})$ was rutile as shown in its XRD pattern in Figure 2 with very intense peaks due to rutile when compared to other XRD patterns. Two new peaks at $2 \theta=43.6^{\circ}$ and $63.6^{\circ}$ assigned to the rutile phase and anatase phase, respectively, appeared in the XRD patterns of all doped samples but were not visible in the XRD patterns of undoped $\mathrm{TiO}_{2}$.

The crystallographic parameters of the synthesised undoped $\mathrm{TiO}_{2}$ obtained from the XRD instrument were as follows: crystal system: tetragonal, space group: $\mathrm{P} 42 / \mathrm{mm}$, space group number: 136 , and lattice constants of $a(\AA), b(\AA)$, 
TABLE 1: Calculated percentages of anatase and rutile phases.

\begin{tabular}{lcc}
\hline Sample & \% of anatase & \% of rutile \\
\hline Undoped $\mathrm{TiO}_{2}$ & 88.13 & 11.88 \\
C-doped $\mathrm{TiO}_{2}(0.0 \% \mathrm{Ag})$ & 2.09 & 97.91 \\
$\mathrm{Ag} / \mathrm{C}$ codoped $\mathrm{TiO}_{2}(0.2 \% \mathrm{Ag})$ & 22.60 & 77.40 \\
$\mathrm{Ag} / \mathrm{C}$ codoped $\mathrm{TiO}_{2}(0.5 \% \mathrm{Ag})$ & 22.95 & 77.05 \\
$\mathrm{Ag} / \mathrm{C}$ codoped $\mathrm{TiO}_{2}(0.7 \% \mathrm{Ag})$ & 2.20 & 97.80 \\
$\mathrm{Ag} / \mathrm{C}$ codoped $\mathrm{TiO}_{2}(1.0 \% \mathrm{Ag})$ & 13.92 & 86.08 \\
\hline
\end{tabular}

and $c(\AA): 4.5928,4.5928$, and 2.9605 , respectively. The volume of the cell was $62.45 \times\left(10^{6} \mathrm{pm}^{3}\right)$. From this information it shows that the prepared $\mathrm{TiO}_{2}$ had no brookite phase but only anatase and rutile.

To estimate the anatase percentage $(A \%)$, the following equation was used for calculations [28].

$$
A \%=\frac{100}{\left(1+1.265\left(I_{r} / I_{a}\right)\right)},
$$

where $I_{r}$ is the peak intensity of rutile at 2 theta' value of $27.4^{\circ}$. $I_{a}$ is the peak intensity of anatase at 2 theta' value of $25.3^{\circ}$.

The calculated percentages of anatase and rutile phases in undoped $\mathrm{TiO}_{2}$ and $\mathrm{Ag} / \mathrm{C}$ codoped $\mathrm{TiO}_{2}$ are shown in Table 1 . When compared to undoped $\mathrm{TiO}_{2}$, the percentage of anatase decreased in all doped samples due to phase transformation to rutile which was related to $\mathrm{Ag}$ or $\mathrm{C}$ doping.

The highest percentage of the anatase phase of $88.13 \%$ and the lowest percentage of rutile of $11.88 \%$ were found in the undoped $\mathrm{TiO}_{2}$ photocatalyst which was also calcined at $500^{\circ} \mathrm{C}$. All the $\mathrm{Ag} / \mathrm{C}$ codoped $\mathrm{TiO}_{2}$ photocatalysts had higher percentages of the rutile phase than the anatase phase. The highest anatase to rutile phase transformation occurred at $500^{\circ} \mathrm{C}$ when $\mathrm{TiO}_{2}$ was doped with carbon only, with less rutile formed in $\mathrm{Ag} / \mathrm{C}$ codoped $\mathrm{TiO}_{2}(0.7 \% \mathrm{Ag})$ photocatalyst with $2.20 \%$ anatase and $97.80 \%$ rutile.

3.3. Raman Analysis. Anatase and rutile phases of $\mathrm{TiO}_{2}$ were also identified by Raman spectroscopy based on their spectra. On the basis of the factor group analysis, the anatase phase has six active modes at $144 \mathrm{~cm}^{-1}\left(\mathrm{E}_{\mathrm{g}}\right), 197 \mathrm{~cm}^{-1}\left(\mathrm{E}_{\mathrm{g}}\right)$, $399 \mathrm{~cm}^{-1}\left(\mathrm{~B}_{\mathrm{lg}}\right), 513 \mathrm{~cm}^{-1}\left(\mathrm{~A}_{\mathrm{lg}}\right), 519 \mathrm{~cm}^{-1}\left(\mathrm{~B}_{\mathrm{lg}}\right)$, and $639 \mathrm{~cm}^{-1}$ $\left(E_{g}\right)$ [29]. The Raman bands typical of the rutile phase appear at $143 \mathrm{~cm}^{-1}$ (normally superimposed with anatase peak at $144 \mathrm{~cm}^{-1}$ ), $235 \mathrm{~cm}^{-1}, 447 \mathrm{~cm}^{-1}$, and $612 \mathrm{~cm}^{-1}$ due to $\mathrm{B}_{1 \mathrm{~g}}$, twophonon scattering (TPS), $\mathrm{E}_{\mathrm{g}}$, and $\mathrm{A}_{\mathrm{gg}}$ modes, respectively [30].

Well defined peaks were observed at $145 \mathrm{~cm}^{-1}\left(\mathrm{E}_{\mathrm{g}}\right)$, $244 \mathrm{~cm}^{-1}, 404 \mathrm{~cm}^{-1}\left(\mathrm{~B}_{\mathrm{lg}}\right)$ prominent in undoped $\mathrm{TiO}_{2}$, $453 \mathrm{~cm}^{-1}\left(\mathrm{E}_{\mathrm{g}}\right), 525 \mathrm{~cm}^{-1}\left(\mathrm{~B}_{\mathrm{lg}}\right), 617 \mathrm{~cm}^{-1}\left(\mathrm{~A}_{\mathrm{lg}}\right)$, and $641 \mathrm{~cm}^{-1}$ $\left(\mathrm{E}_{\mathrm{g}}\right)$ as shown in Figure 3. It is clear that the strongest band for the anatase is at $145 \mathrm{~cm}^{-1}$ in the spectra of undoped $\mathrm{TiO}_{2}$ which slightly shifted to $147 \mathrm{~cm}^{-1}$ in the spectra of doped $\mathrm{TiO}_{2}$. The presence of the peak at $244 \mathrm{~cm}^{-1}$ due to the rutile phase in all doped $\mathrm{TiO}_{2}$ samples except the undoped $\mathrm{TiO}_{2}$ shows that the high temperature of calcination or

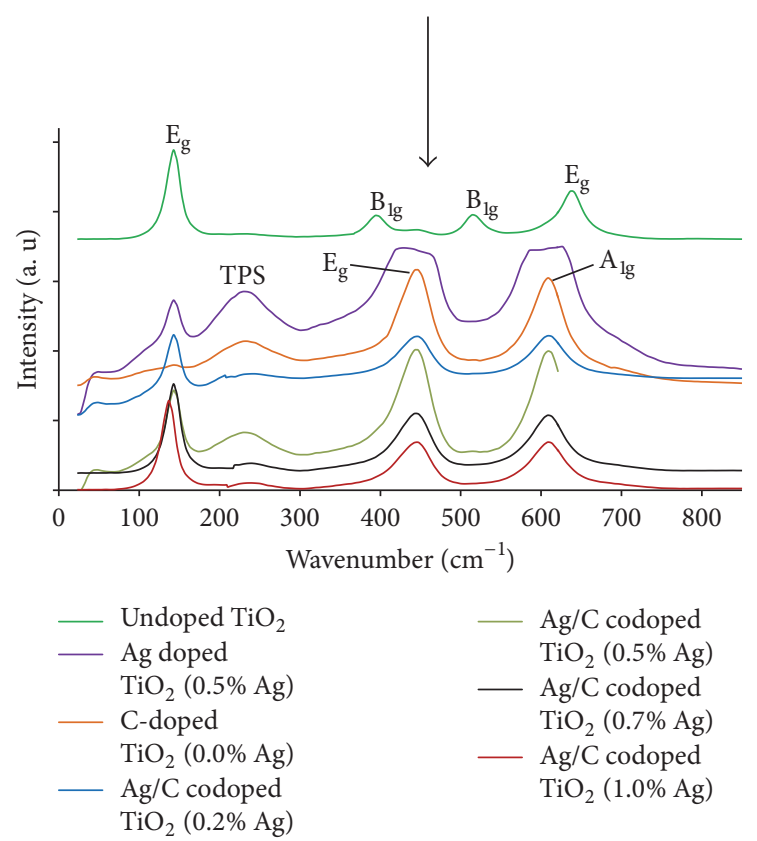

Figure 3: Raman spectra of undoped $\mathrm{TiO}_{2}, \mathrm{Ag}$ doped $\mathrm{TiO}_{2}$, and $\mathrm{Ag} /$ $\mathrm{C}$ codoped $\mathrm{TiO}_{2}$ photocatalysts with different contents of Ag.

introduction of impurities in the structure of $\mathrm{TiO}_{2}$ could have caused the anatase to rutile phase transformation which is in agreement with XRD results. This is also supported by the big reduction in intensities of the anatase peaks at $404 \mathrm{~cm}^{-1}$ and $644 \mathrm{~cm}^{-1}$ and a huge increase in the intensities of the rutile peaks at $453 \mathrm{~cm}^{-1}$ and $617 \mathrm{~cm}^{-1}$ in the spectra of doped $\mathrm{TiO}_{2}$. The vibrational mode of the rutile phase at $143 \mathrm{~cm}^{-1}$ could not be detected probably due to the superimposition with the anatase phase at $144 \mathrm{~cm}^{-1}$. When carbon was used as the only dopant, the $\mathrm{E}_{\mathrm{g}}$ peak at $144 \mathrm{~cm}^{-1}$ nearly disappeared and all its major peaks were due to the rutile phase. This peak is very sensitive to the vibrational mode of the O-Ti-O bond [31].

\subsection{Optical Properties}

3.4.1. Absorbance. The absorption spectra of C-doped $\mathrm{TiO}_{2}$, Ag doped $\mathrm{TiO}_{2}$, undoped $\mathrm{TiO}_{2}$, and $\mathrm{Ag} / \mathrm{C}$ codoped $\mathrm{TiO}_{2}$ with different contents of Ag are shown Figure 4. When compared to undoped $\mathrm{TiO}_{2}$ photocatalyst, the absorption edge of all the $\mathrm{Ag} / \mathrm{C}$ codoped photocatalysts redshifted and the highest shift was observed for the photocatalyst with $0.5 \%$ Ag loading. When the Ag content was increased from $0.5 \%$ to $1.0 \%$, the absorbance blueshifted implying that the optimum loading for Ag in this study to obtain a catalyst that could absorb the most visible light was $0.5 \%$.

3.4.2. UV-Vis Diffuse Reflectance. The diffuse reflectance spectra show a very clear and significant shift of the absorption edges of the doped photocatalysts to higher wavelengths when compared to the undoped $\mathrm{TiO}_{2}$ photocatalyst as shown Figure 5. The reason for the redshift allowing visible light absorption by the photocatalysts could be the introduction 


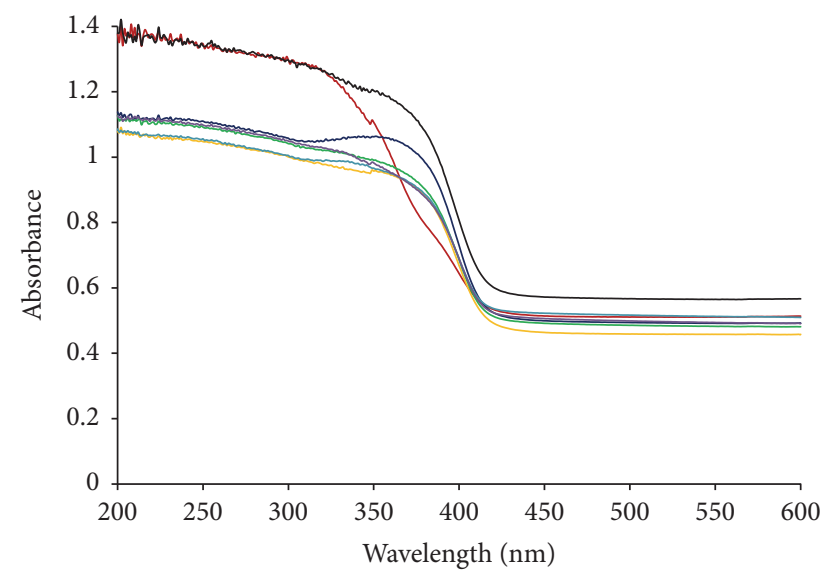

$$
\begin{array}{ll}
\text { - Undoped } \mathrm{TiO}_{2} \\
\text { Ag doped } \\
\mathrm{TiO}_{2}(0.5 \% \mathrm{Ag}) \\
-\mathrm{C} \text {-doped } \\
\mathrm{TiO}_{2}(0.0 \% \mathrm{Ag}) \\
-\mathrm{Ag} / \mathrm{C} \text { codoped } \\
& \mathrm{TiO}_{2}(0.2 \% \mathrm{Ag})
\end{array}
$$

$$
\begin{gathered}
-\mathrm{Ag} / \mathrm{C} \text { codoped } \\
\mathrm{TiO}_{2}(0.5 \% \mathrm{Ag}) \\
\mathrm{Ag} / \mathrm{C} \text { codoped } \\
\mathrm{TiO}_{2}(0.7 \% \mathrm{Ag}) \\
-\mathrm{Ag}^{\mathrm{C}} \text { codoped } \\
\mathrm{TiO}_{2}(1.0 \% \mathrm{Ag})
\end{gathered}
$$

Figure 4: UV-Vis absorption spectra of the undoped $\mathrm{TiO}_{2}, \mathrm{Ag}$ doped $\mathrm{TiO}_{2}$, C-doped $\mathrm{TiO}_{2}$, and $\mathrm{Ag} / \mathrm{C}$ codoped $\mathrm{TiO}_{2}$ photocatalysts with different $\mathrm{Ag}$ loadings.

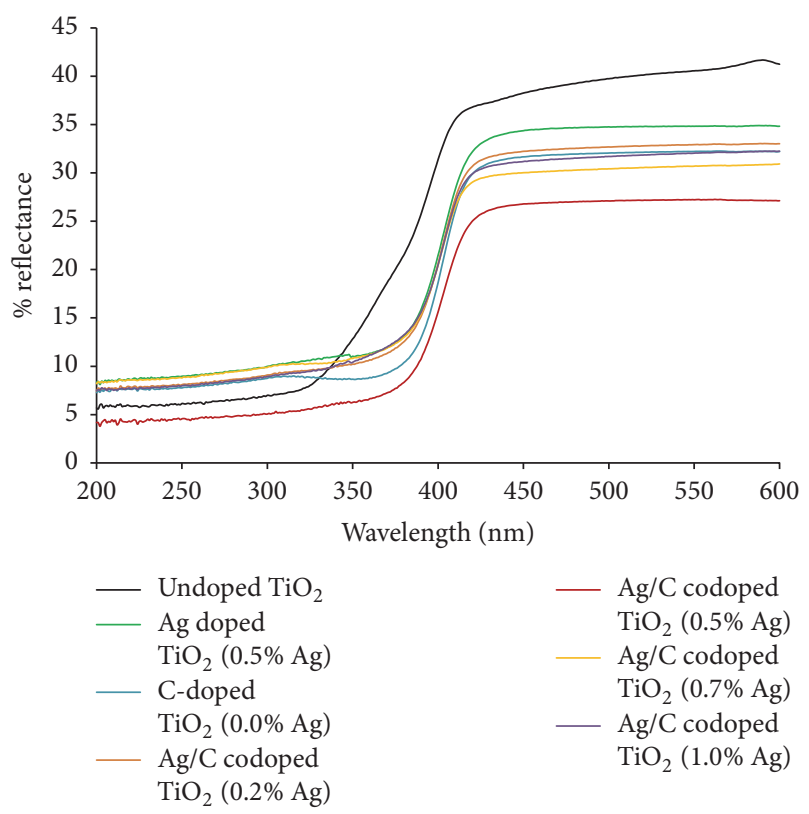

FIgURE 5: UV-Vis diffuse reflectance spectra of undoped $\mathrm{TiO}_{2}, \mathrm{Ag}$ doped $\mathrm{TiO}_{2}$, C-doped $\mathrm{TiO}_{2}$, and $\mathrm{Ag} / \mathrm{C}$ codoped $\mathrm{TiO}_{2}$ photocatalysts with different Ag loadings.

of impurity levels with Ag doping [32]. The electron transfer from one of the additional impurity energy levels within the band gap of the semiconductor requires low photon energy. There were very small differences between the absorption edges of the photocatalysts with $0.2 \%, 0.7 \%$, and $1.0 \% \mathrm{Ag}$ loading. A significant shift was observed for the photocatalyst

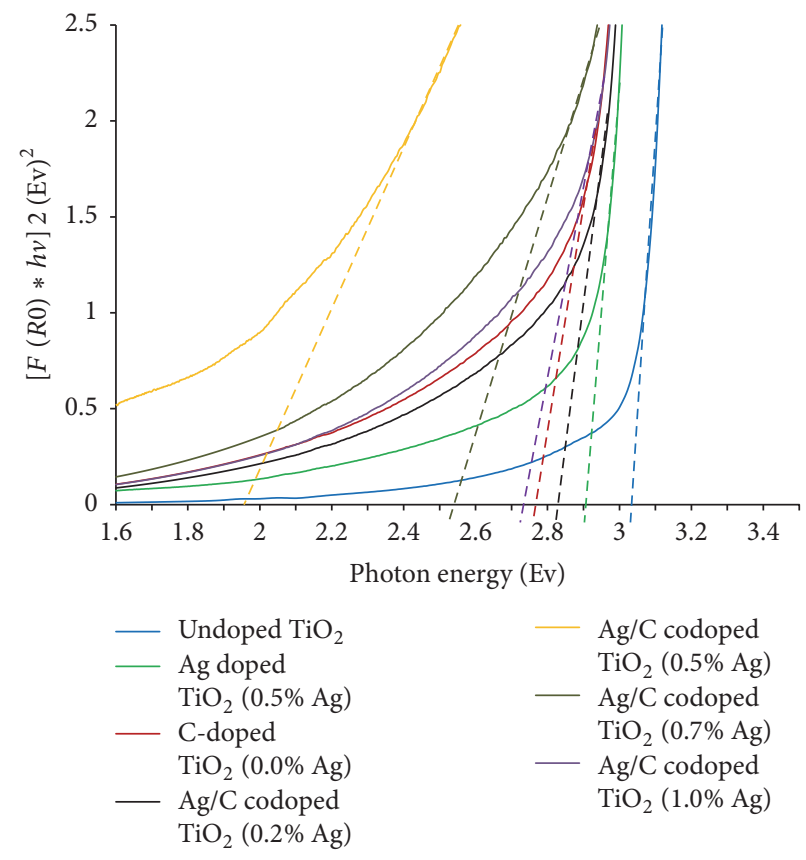

Figure 6: Tauc plots of undoped $\mathrm{TiO}_{2}, \mathrm{Ag}$ doped $\mathrm{TiO}_{2}$, and $\mathrm{Ag} / \mathrm{C}$ codoped $\mathrm{TiO}_{2}$ photocatalysts with different contents of Ag.

with Ag loading of $0.5 \%$. Of all the doped photocatalysts, the one doped with carbon as the only dopant $(0.0 \% \mathrm{Ag})$ showed the least shift, which shows that codoping is better than the use of one dopant in enhancing visible light absorption.

3.4.3. Band Gap Determination. The band gaps were determined using Tauc plots which are plots of $[F(R) * h v]^{1 / 2}$ versus photon energy. The extrapolation to the horizontal axis (energy axis) gave an estimate of the value of the band gap $\left(\mathrm{E}_{\mathrm{g}}\right)$. The Tauc, Davis, and Mott expression is shown in

$$
(h v \alpha)^{1 / n}=A\left(h v-\mathrm{E}_{\mathrm{g}}\right),
$$

where $\alpha$ is the absorption coefficient, $h$ is Plank's constant, $\mathrm{E}_{\mathrm{g}}$ is the band gap, $A$ is the proportionality constant, $v$ is the frequency of vibration, and $n$ is a constant which denotes the nature of the sample preparation. In this study the value of $n$ used for the calculations was 2 since the absorption of $\mathrm{TiO}_{2}$ has an indirect transition.

The Tauc plots of $\mathrm{Ag} / \mathrm{C}$ codoped $\mathrm{TiO}_{2}$ photocatalysts are shown in Figure 6. Undoped $\mathrm{TiO}_{2}$ photocatalyst gave the most well defined absorption edge that made it quite easy to make an extrapolation and determine the band gap more accurately (ca. $3.06 \mathrm{eV}$ ). The band gaps of all the Ag/C codoped $\mathrm{TiO}_{2}$ photocatalysts were between $1.95 \mathrm{eV}$ and $2.90 \mathrm{eV}$ thus lower than that of the undoped $\mathrm{TiO}_{2}$. This band gap narrowing could be attributed to the substitution of carbon and/or metal Ag for oxygen.

There was a decrease in the band gap from $2.83 \mathrm{eV}$ to $1.95 \mathrm{eV}$ as the $\mathrm{Ag}$ loading was increased from $0.2 \%$ to $0.5 \%$ and any further increase in the Ag loading caused band gap widening (Table 2). The possible reason for the increase in band gap with an increase in Ag content was the dominance 


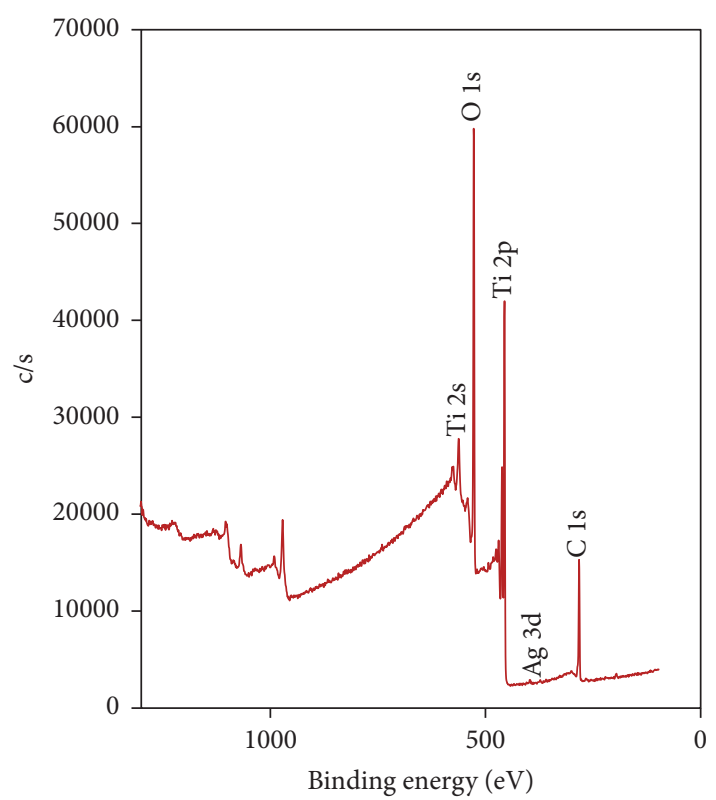

(a)

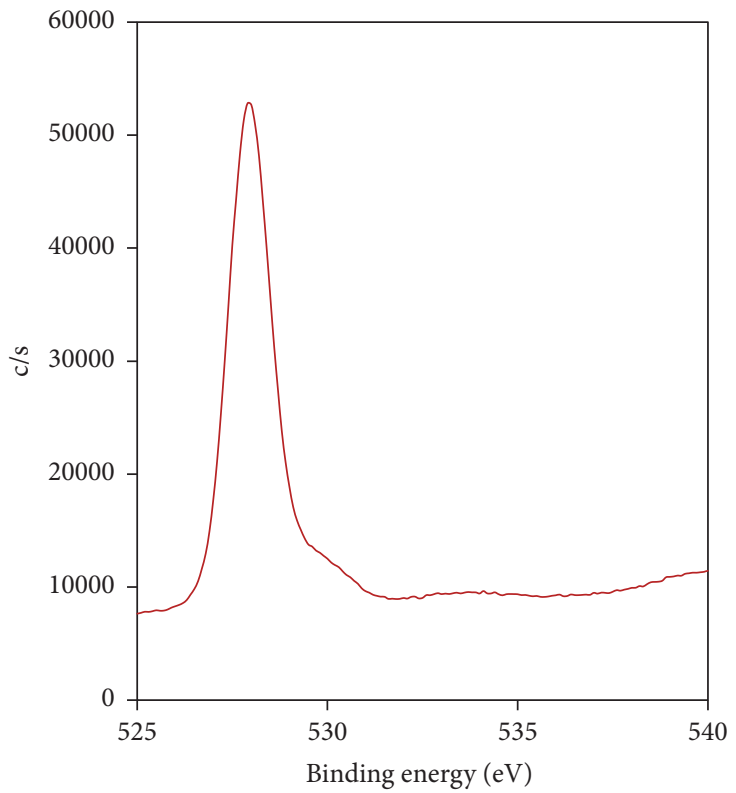

(c)

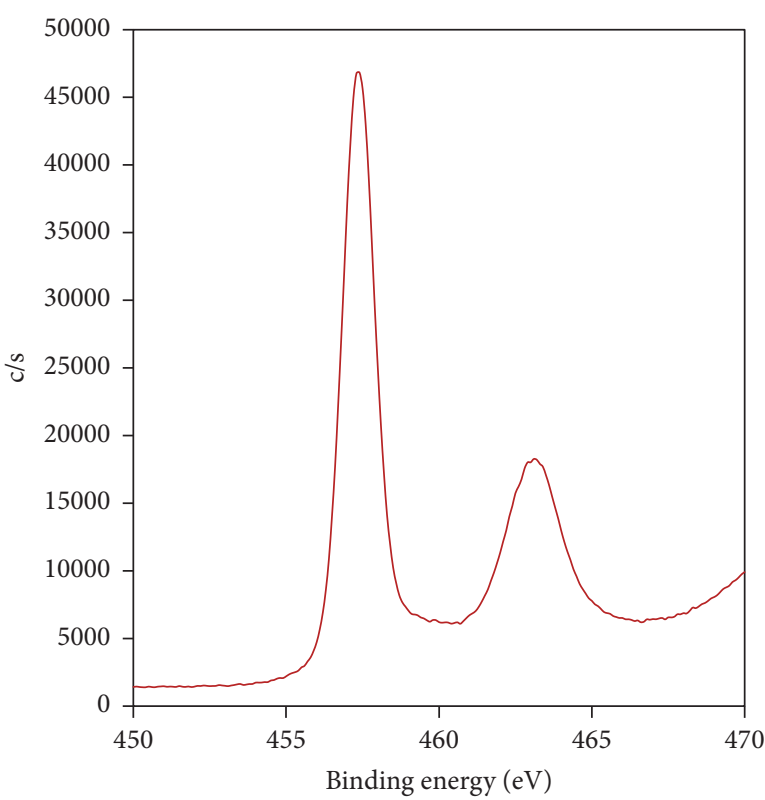

(b)

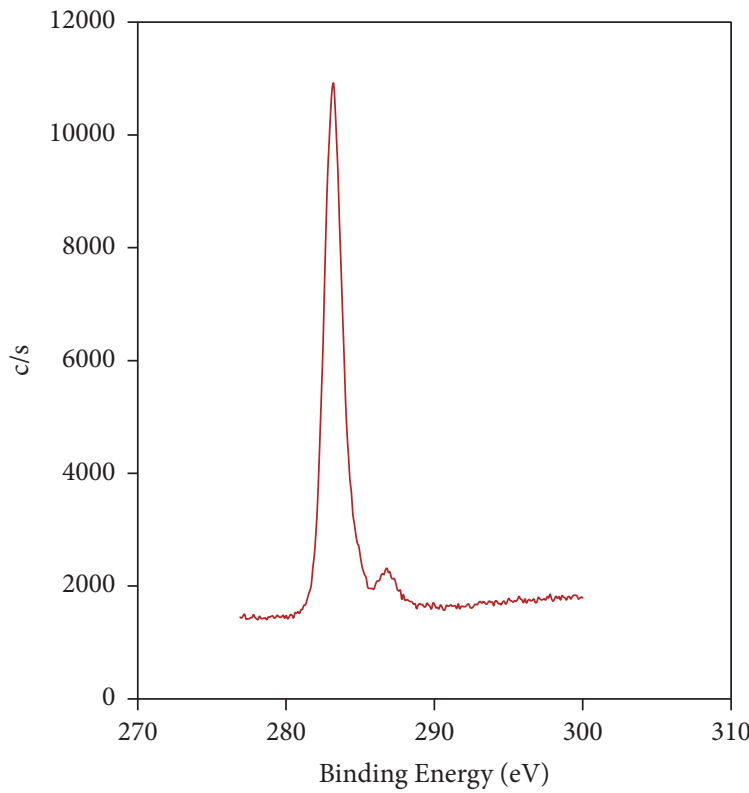

(d)

Figure 7: XPS spectra of $\mathrm{Ag} / \mathrm{C}$ codoped $\mathrm{TiO}_{2}(0.5 \% \mathrm{Ag})$ photocatalyst; (a) survey scan, (b) $\mathrm{Ti} 2 \mathrm{p},(\mathrm{c}) \mathrm{O}$ 1s, and (d) C $1 \mathrm{~s}$.

of the $d$ - $d$ transitions over the sp- $d$ transitions. The optimum loading of silver in this study for codoping $\mathrm{TiO}_{2}$ with silver and carbon was found to be $0.5 \%$. It is important to note that new occupied bands could have been formed as a result of the hybridization of $\mathrm{Ag} 4 \mathrm{~d}$ and $\mathrm{Ti} 3 \mathrm{~d}$ states.

3.5. XPS Analysis. The presence of carbon and silver in $\mathrm{TiO}_{2}$ was revealed by XPS analysis. The high resolution XPS scans over the $\mathrm{Ti} 2 \mathrm{p}, \mathrm{O} 1 \mathrm{~s}$, and $\mathrm{C}$ 1s in $\mathrm{Ag} / \mathrm{C}$ codoped $\mathrm{TiO}_{2}(0.5 \%$ $\mathrm{Ag})$ photocatalyst are shown in Figure 7.

The spectra show that the $\mathrm{Ag} / \mathrm{C}$ codoped $\mathrm{TiO}_{2}$ photocatalyst contained the elements carbon, titanium, oxygen, and silver. The XPS spectrum of Ti $2 p$ (Figure 7(b)) shows two peaks at binding energies of $457.5 \mathrm{eV}$ and $463.5 \mathrm{eV}$ which were attributed to the spin orbit coupling of Ti $2 \mathrm{p}_{3 / 2}$ and Ti $2 \mathrm{p}_{1 / 2}$, respectively, and the binding energy separation between these peaks was $6 \mathrm{eV}$ which is characteristic for $\mathrm{TiO}_{2}$ [33]. The peak at $564 \mathrm{eV}$ was due to $\mathrm{Ti} 2 \mathrm{~s}$ (Figure 7 (a)) and was not as intense as the $\mathrm{Ti} 2 \mathrm{p}$ peak. The peak intensity of $\mathrm{Ti}^{4+}$ was much higher than that of other species implying that, in the $\mathrm{TiO}_{2}$ lattice, $\mathrm{Ti}^{4+}$ was dominant. When $\mathrm{Ag}^{+}$replaces $\mathrm{Ti}$ in the lattice, it causes oxygen vacancies which result in some changes of $\mathrm{Ti}^{4+}$ ions into $\mathrm{Ti}^{3+}$ ions [34]. From the survey scan, only $0.13 \%$ of $\mathrm{Ag}$ was detected in the codoped $\mathrm{TiO}_{2}$ and this can be 
TABle 2: Band gaps of undoped $\mathrm{TiO}_{2}$, Ag doped $\mathrm{TiO}_{2}$, and $\mathrm{Ag} / \mathrm{C}$ codoped $\mathrm{TiO}_{2}$ with different contents of $\mathrm{Ag}$.

\begin{tabular}{lc}
\hline Sample & Band gaps from Tauc plots \\
\hline Undoped $\mathrm{TiO}_{2}$ & 3.06 \\
Ag doped $\mathrm{TiO}_{2}$ & 2.90 \\
C-doped $\mathrm{TiO}_{2}(0.0 \% \mathrm{Ag})$ & 2.77 \\
$\mathrm{Ag} / \mathrm{C}$ codoped $\mathrm{TiO}_{2}(0.2 \% \mathrm{Ag})$ & 2.83 \\
$\mathrm{Ag} / \mathrm{C}$ codoped $\mathrm{TiO}_{2}(0.5 \% \mathrm{Ag})$ & 1.95 \\
$\mathrm{Ag} / \mathrm{C}$ codoped $\mathrm{TiO}_{2}(0.7 \% \mathrm{Ag})$ & 2.53 \\
Ag/C codoped $\mathrm{TiO}_{2}(1.0 \% \mathrm{Ag})$ & 2.72 \\
\hline
\end{tabular}

TABLE 3: BET surface area, pore volume, and pore size of undoped $\mathrm{TiO}_{2}$ and $\mathrm{Ag} / \mathrm{C}$ codoped $\mathrm{TiO}_{2}$ photocatalysts.

\begin{tabular}{lcc}
\hline Sample & $\begin{array}{c}\text { BET surface } \\
\text { area }\left(\mathrm{m}^{2} \mathrm{~g}^{-1}\right)\end{array}$ & $\begin{array}{c}\text { Pore volume } \\
\left(\mathrm{cm}^{3} \mathrm{~g}^{-1}\right)\end{array}$ \\
\hline Pure $\mathrm{TiO}_{2}$ & 68.97 & 0.28 \\
C-doped $\mathrm{TiO}_{2}(0.0 \% \mathrm{Ag})$ & 83.14 & 0.23 \\
$\mathrm{Ag} / \mathrm{C}$ codoped $\mathrm{TiO}_{2}(0.2 \% \mathrm{Ag})$ & 11.14 & 0.10 \\
$\mathrm{Ag} / \mathrm{C}$ codoped $\mathrm{TiO}_{2}(0.5 \% \mathrm{Ag})$ & 15.07 & 0.13 \\
$\mathrm{Ag} / \mathrm{C}$ codoped $\mathrm{TiO}_{2}(0.7 \% \mathrm{Ag})$ & 32.00 & 0.28 \\
$\mathrm{Ag} / \mathrm{C}$ codoped $\mathrm{TiO}_{2}(1.0 \% \mathrm{Ag})$ & 28.66 & 0.13 \\
\hline
\end{tabular}

explained by the radius of $\mathrm{Ag}^{+}$(ca. $126 \AA$ ) which is larger than that of $\mathrm{Ti}^{4+}$ (ca. $68 \AA$ ) thus making replacement of $\mathrm{Ag}$ into the $\mathrm{TiO}_{2}$ lattice difficult and requiring energy.

The O (1s) XPS spectrum (Figure 7(c)) consists of one major peak at $528 \mathrm{eV}$ and a shoulder at $530.5 \mathrm{eV}$ which corresponds to oxygen bound to $\mathrm{TiO}_{2}(\mathrm{O}-\mathrm{Ti}-\mathrm{O})$ and surface hydroxyl groups (T-OH), respectively. The $\mathrm{C}$ 1s of the prepared $\mathrm{Ag} / \mathrm{C}$ codoped $(0.5 \% \mathrm{Ag})$ photocatalyst revealed two peaks at binding energies of $283.2 \mathrm{eV}$ and $287.3 \mathrm{eV}$ (Figure 7(d)). The peak at $283.2 \mathrm{eV}$ can be assigned to carbon that substituted an oxygen atom in the crystal lattice of $\mathrm{TiO}_{2}$ forming C-Ti-O bond [35]. In this study the peak at $287.3 \mathrm{eV}$ can be attributed to C-O bond; hence the XPS spectrum proved that some $\mathrm{C}$ was doped into the $\mathrm{TiO}_{2}$ lattice.

3.6. BET Surface Analysis. The differences in the surface area and porosity of particles of the same material, which may otherwise have the same physical characteristics, can greatly influence its performance characteristics. The highest surface area of $83.13 \mathrm{~m}^{2} \mathrm{~g}^{-1}$ was achieved when carbon was used as the only dopant implying that carbon doping increases the surface area of $\mathrm{TiO}_{2}$ (Table 3). The surface area of the $\mathrm{Ag} / \mathrm{C}$ codoped $\mathrm{TiO}_{2}$ photocatalysts increased slightly with an increase in the silver content and decreased with silver contents above $0.7 \%$. It is believed that a photocatalyst with high surface area is desirable in photocatalysis since high surface areas allow greater adsorption of pollutants resulting in enhancement of photocatalytic activity.

3.7. Thermal Properties. The powdered samples $(10 \mathrm{mg})$ were heated from $20^{\circ} \mathrm{C}$ to $800^{\circ} \mathrm{C}$ at a heating rate of $20^{\circ} \mathrm{C} / \mathrm{min}$ in

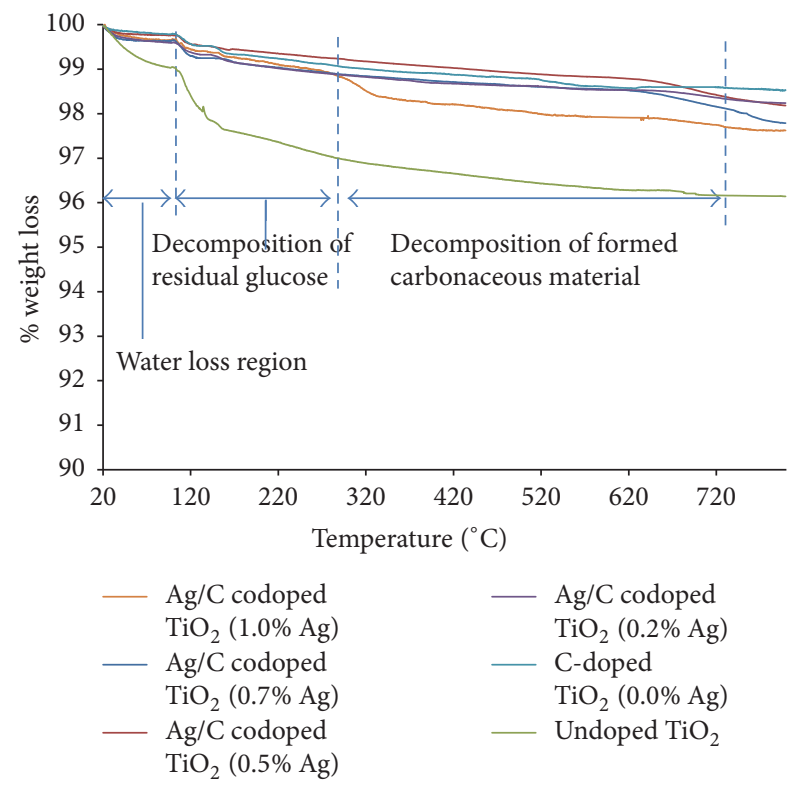

Figure 8: Thermograms of undoped $\mathrm{TiO}_{2}$, C-doped $\mathrm{TiO}_{2}$, and $\mathrm{Ag} / \mathrm{C}$ codoped $\mathrm{TiO}_{2}$ photocatalysts with different Ag contents.

a nitrogen environment. The thermograms showing the percentage weight loss with increasing temperature are shown in Figure 8.

All the samples started showing a mass loss at around $100^{\circ} \mathrm{C}$ due to loss of adsorbed water on the $\mathrm{TiO}_{2}$ surface. The highest weight loss of $3.83 \%$ was seen in undoped $\mathrm{TiO}_{2}$. There was a gradual increase in total weight loss at $800^{\circ} \mathrm{C}$ with an increase in $\mathrm{Ag}$ content. The $\mathrm{TiO}_{2}$ with $0.0 \% \mathrm{Ag}$ showed a total weight loss of $1.46 \%$ whereas the $\mathrm{TiO}_{2}$ photocatalyst with $1.0 \%$ Ag showed 2.36\% weight loss. Since the total mass loss in all cases was less than $3.83 \%$, it suggests that the photocatalysts were thermally stable and most of the carbonaceous material from glucose (C-dopant source) was lost during the pyrolysis process, since the decomposition process of glucose started at $120^{\circ} \mathrm{C}$ and pyrolysis started at $320^{\circ} \mathrm{C}$ up to $800^{\circ} \mathrm{C}$.

\section{Photocatalytic Activity Evaluation}

The highest photodegradation of methyl orange under visible light was achieved by C-doped $\mathrm{TiO}_{2}(0.0 \% \mathrm{Ag})$ photocatalyst probably due to the high surface area for adsorption of the contaminant and also enhanced visible light absorption. There was an increase in the photodegradation of methyl orange from $47.61 \%$ to $52.07 \%$ when the $\mathrm{Ag}$ content was increased from $0.2 \%$ to $0.5 \%$ and it decreased with a further increase in $\mathrm{Ag}$ content of $0.7 \%$ (Figure 9). The optimum loading of $\mathrm{Ag}$ in the codoped $\mathrm{TiO}_{2}$ for efficient photocatalysis in this study was found to be $0.5 \%$. The reason for the high photodegradation rates from this photocatalyst could be the low band gap of $1.95 \mathrm{eV}$ allowing efficient visible light absorption. It is important to note that the material with a lower band gap will not always have higher photocatalytic activity as expected. For instance, the photocatalytic activity of $\mathrm{Ag} / \mathrm{C}-\mathrm{TiO}_{2}(0.7 \%)$ with a calculated band gap of $2.53 \mathrm{eV}$ 


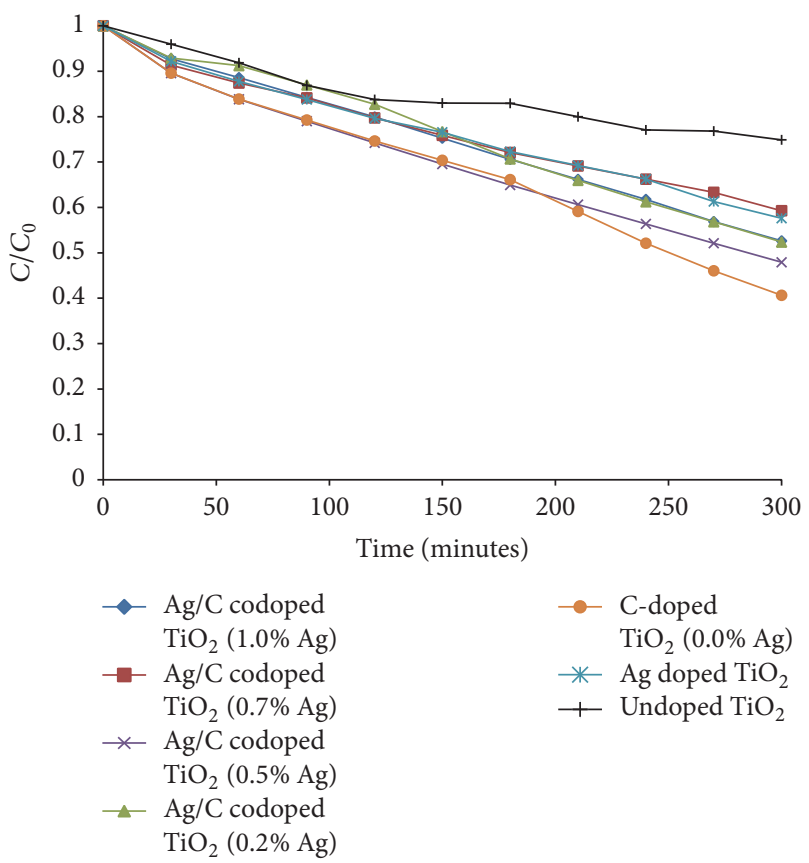

FIGURE 9: Photodegradation of $10 \mathrm{ppm}$ methyl orange solution using Ag/C codoped $\mathrm{TiO}_{2}$ photocatalysts with different contents of $\mathrm{Ag}$ under visible light irradiation at $25^{\circ} \mathrm{C}$ and $\mathrm{pH} 7$.

was lower than that of $\mathrm{Ag} / \mathrm{C}-\mathrm{TiO}_{2}(1.0 \%)$ with a band gap of $2.72 \mathrm{eV}$ which was unexpected on the basis of band gaps. This observation points out that band gap narrowing could improve visible light absorption but without improving photocatalytic activity under visible light irradiation. This implies that there could be other factors which override band gap narrowing that affect photocatalytic activity of $\mathrm{TiO}_{2}$ including electron-hole recombination rates, hydrophilicity, and enhanced adsorption due to different surface areas and surface properties.

The general high photocatalytic activity of all the doped $\mathrm{TiO}_{2}$ photocatalysts could be explained by the formation of oxygen vacancies induced by $\mathrm{Ag}^{+}$ions and trapping of electrons by $\mathrm{Ag}^{+}$through the introduction of allowed electronic states below the $\mathrm{TiO}_{2}$ conduction band [36]. This resulted in enhanced visible light absorption and reduced recombination rates of the charge carriers.

\section{Conclusions}

$\mathrm{Ag} / \mathrm{C}$ codoped $\mathrm{TiO}_{2}$ photocatalysts were successfully prepared by a simple sol-gel technique and deposited on quartz substrates. The study showed that a photocatalyst with a low band gap does not always have better photocatalytic activity than wide band gap photocatalysts under visible light irradiation as expected. $\mathrm{TiO}_{2}$ photocatalyst with a significant low band gap of about $1.95 \mathrm{eV}$ can be prepared by codoping with carbon and silver $(0.5 \% \mathrm{Ag})$ and codoping does not always give the best photocatalyst as expected when compared to doping with a single element. The study also showed that there are other factors that override band gap narrowing in enhancing the overall efficiency of the photocatalyst.

\section{Competing Interests}

The authors declare that they have no competing interests.

\section{Acknowledgments}

The authors are thankful to NRF-Sasol Inzalo (South Africa), Environmental and Nano Sciences Group (ENS), Water Research Commission (WRC), and Govan Mbeki Research and Development Centre (GRMDC) for the financial support.

\section{References}

[1] J. Podporska-Carroll, E. Panaitescu, B. Quilty, L. Wang, L. Menon, and S. C. Pillai, "Antimicrobial properties of highly efficient photocatalytic $\mathrm{TiO}_{2}$ nanotubes," Applied Catalysis B: Environmental, vol. 176-177, pp. 70-75, 2015.

[2] M. García-Martínez, I. Da Riva, L. Canoiraa, J. Llamas, R. Alcántara, and J. Gallego, "Photodegradation of polycyclic aromatic hydrocarbons in fossil fuels catalysed by supported $\mathrm{TiO}_{2}$," Applied Catalysis B: Environmental, vol. 67, no. 3-4, pp. 279-289, 2006.

[3] A. Fujishima, T. N. Rao, and D. A. Tryk, "Titanium dioxide photocatalysis," Journal of Photochemistry and Photobiology C: Photochemistry Reviews, vol. 1, no. 1, pp. 1-21, 2000.

[4] J. Y. Choi, K. H. Kim, K. C. Choy, K. T. Oh, and K. N. Kim, "Photocatalytic antibacterial effect of $\mathrm{TiO}_{2}$ film formed on Ti and TiAg exposed to Lactobacillus acidophilus," Journal of Biomedical Materials Research Part B: Applied Biomaterials, vol. 80, no. 2, pp. 353-359, 2007.

[5] T. Verdier, M. Coutand, A. Bertron, and C. Roques, "Antibacterial activity of $\mathrm{TiO}_{2}$ photocatalyst alone or in coatings on E. coli: the influence of methodological aspects," Coatings, vol. 4, no. 3, pp. 670-686, 2014.

[6] K. Hirano, E. Suzuki, A. Ishikawa, T. Moroi, H. Shiroishi, and M. Kaneko, "Sensitization of $\mathrm{TiO}_{2}$ particles by dyes to achieve $\mathrm{H}_{2}$ evolution by visible light," Journal of Photochemistry and Photobiology A: Chemistry, vol. 136, no. 3, pp. 157-161, 2000.

[7] S. Lee and S. Park, "TiO2 photocatalyst for water treatment applications," Journal of Industrial and Engineering Chemistry, vol. 19, no. 6, pp. 1761-1769, 2013.

[8] A. Fujishima, X. Zhang, and D. A. Tryk, "Heterogeneous photocatalysis: from water photolysis to applications in environmental cleanup," International Journal of Hydrogen Energy, vol. 32, no. 14, pp. 2664-2672, 2007.

[9] K. Y. Song, M. K. Park, Y. T. Kwon, H. W. Lee, W. J. Chung, and W. I. Lee, "Preparation of transparent particulate $\mathrm{MoO}_{3} / \mathrm{TiO}_{2}$ and $\mathrm{WO}_{3} / \mathrm{TiO}_{2}$ films and their photocatalytic properties," Chemistry of Materials, vol. 13, no. 7, pp. 2349-2355, 2001.

[10] A. Mills and A. J. Hunte, "An overview of semiconductor photocatalysis," Journal of Photochemistry and Photobiology A: Chemistry, vol. 108, no. 1, pp. 1-35, 1997.

[11] Z. Liu, W. Hou, P. Pavaskar, M. Aykol, and S. B. Cronin, "Plasmon resonant enhancement of photocatalytic water splitting under visible illumination," Nano Letters, vol. 11, no. 3, pp. 11111116, 2011. 
[12] J. Yu, P. Zhang, H. Yu, and C. Trapalis, "Environmental photocatalysis," International Journal of Photoenergy, vol. 2012, Article ID 594214, 4 pages, 2012.

[13] Y. Wen and H. Ding, "Preparation and photocatalytic activity of $\mathrm{Ag} @ \mathrm{AgCl}$ modified natase $\mathrm{TiO}_{2}$ nanotubes," Chinese Journal of Catalysis, vol. 32, no. 1-2, pp. 36-45, 2011.

[14] D. N. Furlong, D. Wells, and W. H. F. Sasse, "Colloidal semiconductors in systems for the sacrificial photolysis of water: sensitization of $\mathrm{TiO}_{2}$ by adsorption of ruthenium complexes," The Journal of Physical Chemistry, vol. 90, no. 6, pp. 1107-1115, 1986.

[15] B. Xin, L. Jing, Z. Ren, B. Wang, and H. Fu, "Effects of simultaneously doped and deposited $\mathrm{Ag}$ on the photocatalytic activity and surface states of $\mathrm{TiO}_{2}$," Journal of Physical Chemistry $B$, vol. 109, no. 7, pp. 2805-2809, 2005.

[16] S. I. Shah, W. Li, C. Huang, O. Jung, and C. Ni, "Study of $\mathrm{Nd}^{3+}$, $\mathrm{Pd}^{2+}, \mathrm{Pt}^{4+}$, and $\mathrm{Fe}^{3+}$ dopant effect on photoreactivity of $\mathrm{TiO}_{2}$ nanoparticles," Proceedings of the National Academy of Sciences, vol. 99, no. 2, pp. 6482-6486, 2002.

[17] K. M. Rahulan, S. Ganesan, and P. Aruna, "Synthesis and optical limiting studies of Au-doped $\mathrm{TiO}_{2}$ nanoparticles," Advances in Natural Sciences: Nanoscience and Nanotechnology, vol. 2, pp. 16, 2011.

[18] M. Subramanian, S. Vijayalakshmi, S. Venkataraj, and R. Jayavel, "Effect of cobalt doping on the structural and optical properties of $\mathrm{TiO}_{2}$ films prepared by sol-gel process," Thin Solid Films, vol. 516, no. 12, pp. 3776-3782, 2008.

[19] P. Nyamukamba, L. Tichagwa, and C. Greyling, "The influence of carbon doping on $\mathrm{TiO}_{2}$ nanoparticle size, surface area, anatase to rutile phase transformation and photocatalytic activity," Materials Science Forum, vol. 712, pp. 49-63, 2012.

[20] H. H. Mungondori and L. Tichagwa, "Photo-catalytic activity of carbon/nitrogen doped $\mathrm{TiO}_{2}-\mathrm{SiO}_{2}$ under UV and visible light irradiation," Materials Science Forum, vol. 734, pp. 226-236, 2013.

[21] C. Di Valentine, E. Finazzi, G. Pacchioni et al., "Density functional theory and electron paramagnetic resonance study on the effect of N-F codoping of $\mathrm{TiO}_{2}$," Chemistry of Materials, vol. 20, no. 11, pp. 3706-3714, 2008.

[22] O. Diwald, T. L. Thompson, T. Zubkov, E. G. Goralski, S. D. Walck, and J. T. Yates Jr., "Photochemical activity of nitrogendoped rutile $\mathrm{TiO}_{2}(110)$ in visible light," The Journal of Physical Chemistry B, vol. 108, no. 19, pp. 6004-6008, 2004.

[23] K. Nakata and A. Fujishima, " $\mathrm{TiO}_{2}$ photocatalysis: design and applications," Journal of Photochemistry and Photobiology C: Photochemistry Reviews, vol. 13, no. 3, pp. 169-189, 2012.

[24] A. R. Markelonis, J. S. Wang, B. Ullrich, C. M. Wai, and G. J. Brown, "Nanoparticle film deposition using a simple and fast centrifuge sedimentation method," Applied Nanoscience, vol. 5, no. 4, pp. 457-468, 2015.

[25] R. L. Frost, "An infrared and Raman spectroscopic study of the uranyl micas," Spectrochimica Acta-Part A: Molecular and Biomolecular Spectroscopy, vol. 60, no. 7, pp. 1469-1480, 2004.

[26] K. Palanivelu, J. Im, and Y. Lee, "Carbon doping of $\mathrm{TiO}_{2}$ for visible light photo catalysis-a review," Carbon Letters, vol. 8, no. 3, pp. 214-224, 2007.

[27] G. An, C. Yang, Y. Zhou, and X. Zhao, "Plasmon-enhanced photoluminescence from $\mathrm{TiO}_{2}: \mathrm{Sm}^{3+}$ :Au nanostructure," Physica Status Solidi A, vol. 209, no. 12, pp. 2583-2588, 2012.

[28] Q. Lu, Z. B. Zhang, C. Q. Dong, X. Y. Zhang, and F. M. Cui, "Improved visible-light photocatalytic activity of bi-crystalline mesoporous titania codoped with carbon and silver," Journal of Inorganic Materials, vol. 12, pp. 1333-1338, 2014.

[29] J. Zhang, M. Li, Z. Feng, J. Chen, and C. Li, "UV Raman spectroscopic study on $\mathrm{TiO}_{2}$. I. Phase transformation at the surface and in the bulk," The Journal of Physical Chemistry B, vol. 110, no. 2, pp. 927-935, 2006.

[30] A. Chaves, R. S. Katiyar, and S. P. S. Porto, "Coupled modes with $\mathrm{A}_{1}$ symmetry in tetragonal $\mathrm{BaTiO}_{3}$," Physical Review B, vol. 10, no. 8, pp. 3522-3533, 1974.

[31] H. Y. Lin, Y. Y. Chou, C. L. Cheng, and Y. F. Chen, "Giant enhancement of band edge emission based on $\mathrm{ZnO} / \mathrm{TiO}_{2}$ nanocomposites," Optics Express, vol. 15, no. 21, pp. 13832-13837, 2007.

[32] M. Harikishore, M. Sandhyarani, K. Venkateswarlu, T. A. Nellaippan, and N. Rameshbabu, "Effect of Ag doping on antibacterial and photocatalytic activity of nanocrystalline $\mathrm{TiO}_{2}$," Procedia Materials Science, vol. 6, pp. 557-566, 2014.

[33] A. M. Abdullah, N. J. Al-Thani, K. Tawbi, and H. Al-Kandari, "Carbon/nitrogen-doped $\mathrm{TiO}_{2}$ : new synthesis route, characterization and application for phenol degradation," Arabian Journal of Chemistry, vol. 9, no. 2, pp. 229-237, 2016.

[34] T.-D. Pham and B.-K. Lee, "Feasibility of silver doped $\mathrm{TiO}_{2}$ /glass fiber photocatalyst under visible irradiation as an indoor air germicide," International Journal of Environmental Research and Public Health, vol. 11, no. 3, pp. 3271-3288, 2014.

[35] Y. Huang, W. K. Ho, S. C. Lee, L. Z. Zhang, G. S. Li, and J. C. Yu, "Effect of carbon doping on the mesoporous structure of nanocrystalline titanium dioxide and its solar-light-driven photocatalytic degradation of $\mathrm{NO}_{x}$, "Langmuir, vol. 24, no. 7, pp. 3510-3516, 2008.

[36] L. M. Santos, W. A. Machado, M. D. França et al., "Structural characterization of Ag-doped $\mathrm{TiO}_{2}$ with enhanced photocatalytic activity," RSC Advances, vol. 5, no. 125, pp. 103752-103759, 2015. 

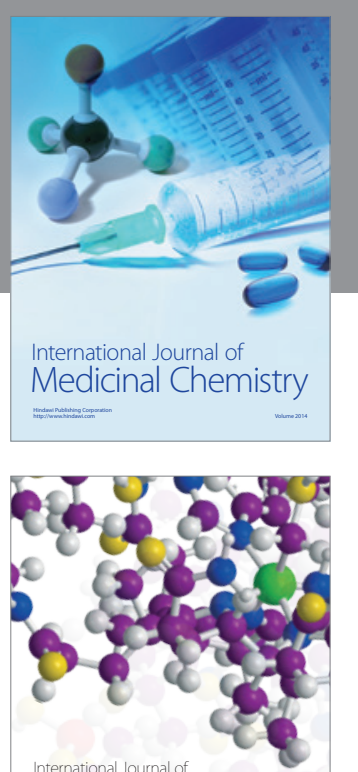

Carbohydrate Chemistry

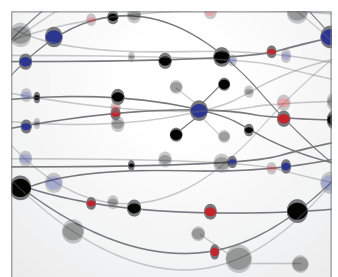

The Scientific World Journal
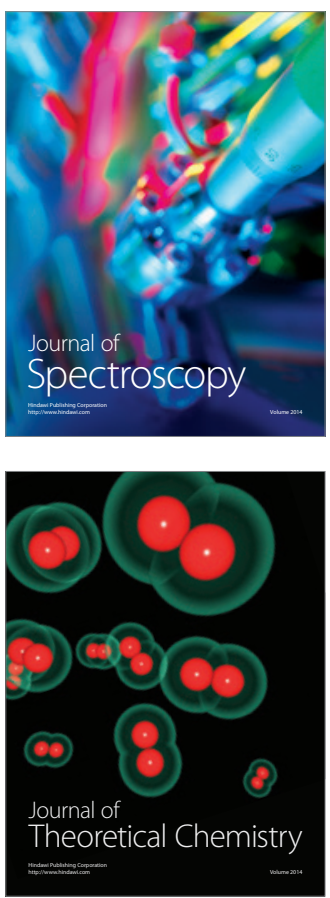
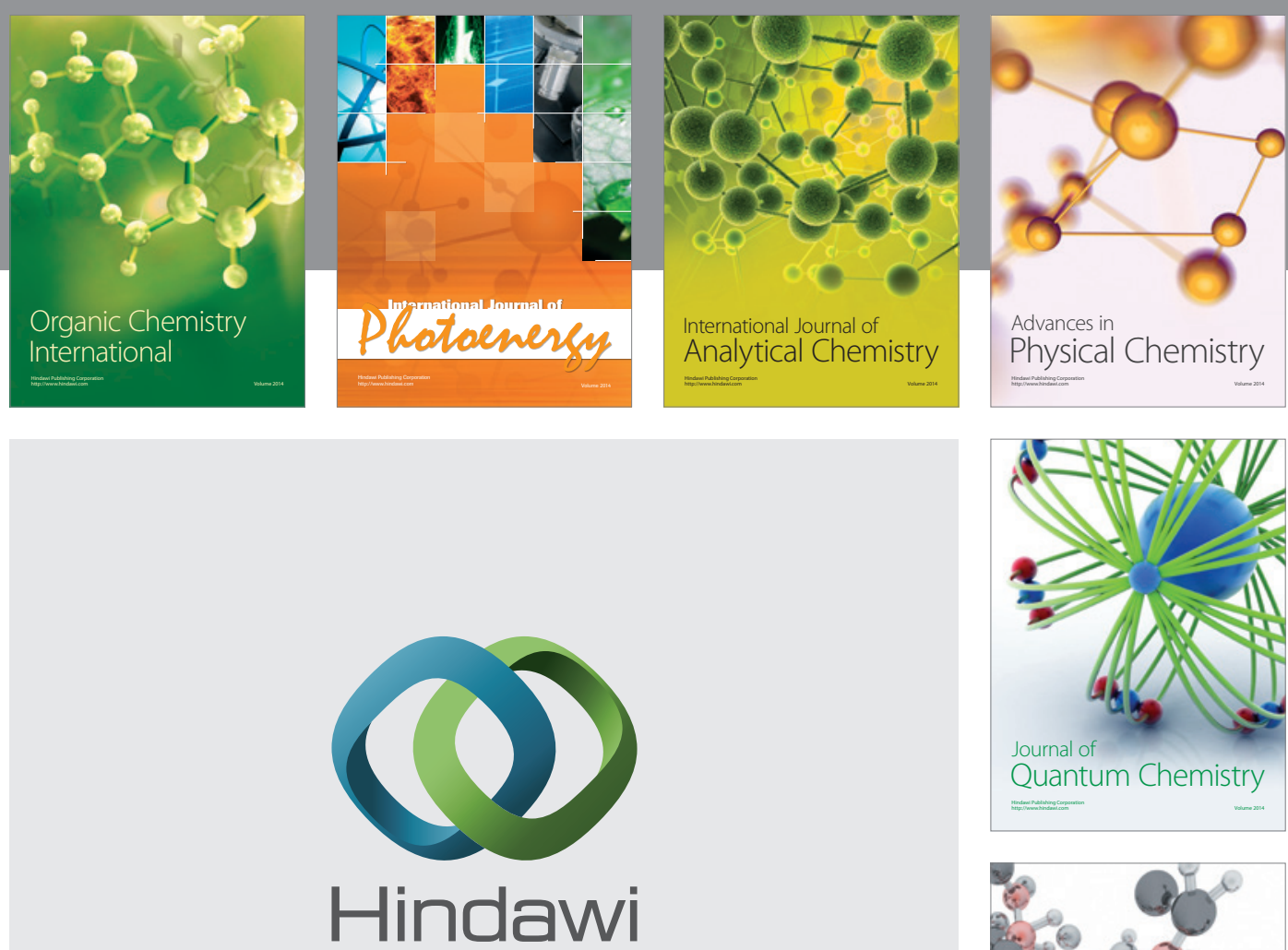

Submit your manuscripts at

https://www.hindawi.com

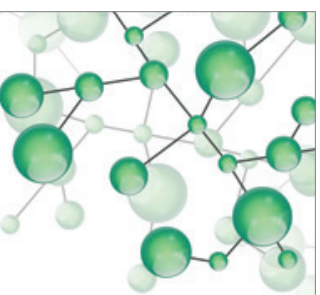

International Journal of

Inorganic Chemistry
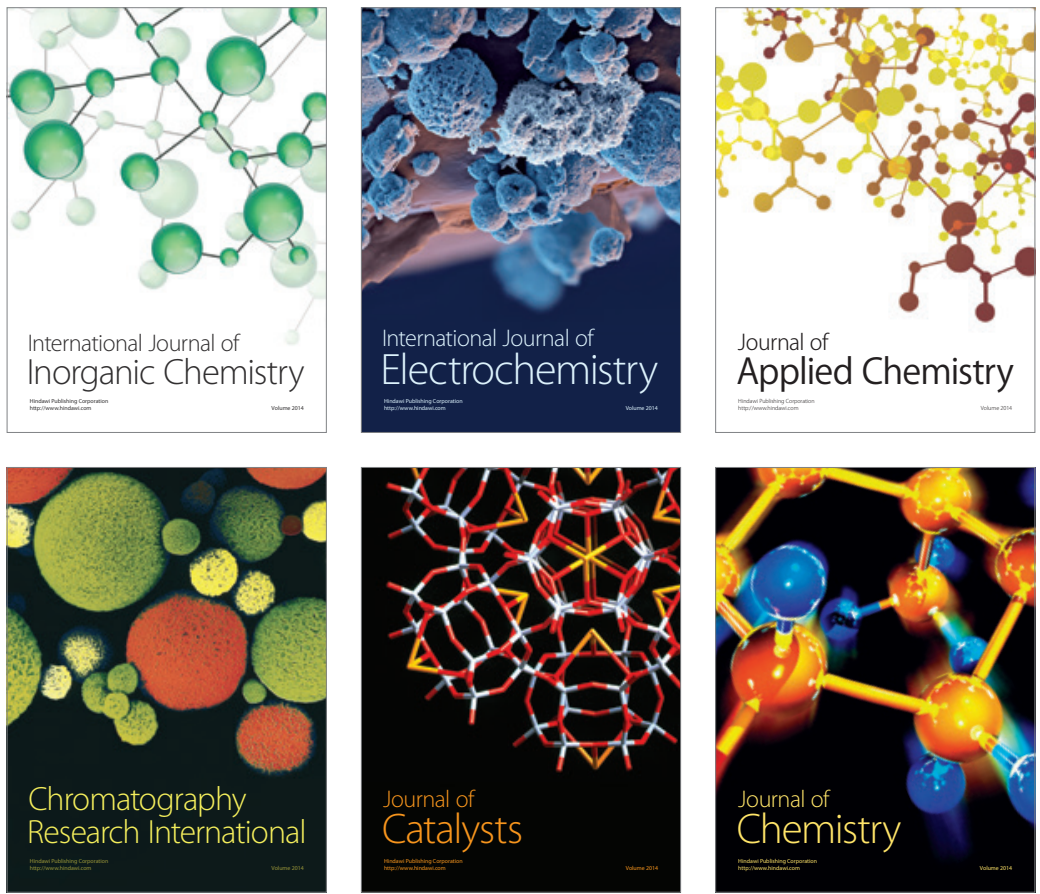

Journal of

Applied Chemistry
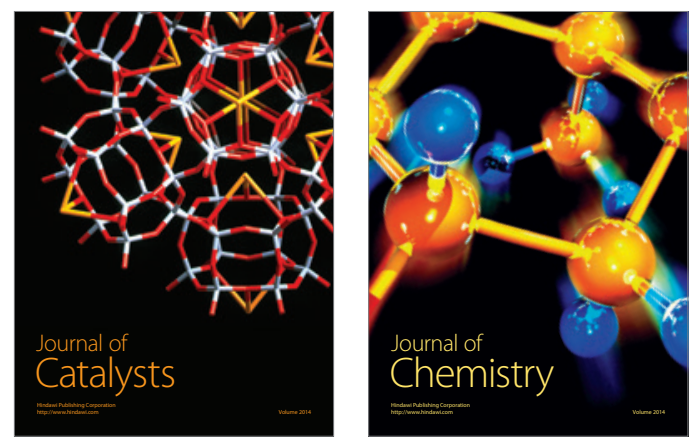
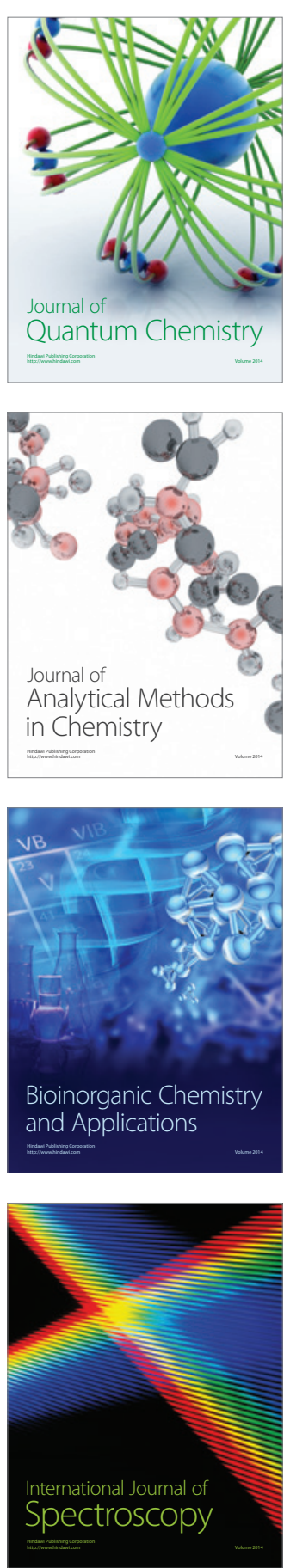